\title{
Health Determinants and Unmet Needs for Health Care- towards e-Health Systems
}

\author{
Georgeta-Madalina MEGHISAN- TOMA \\ The Bucharest University of Economic Studies, Faculty of Business Administration in foreign \\ languages, Bucharest, Romania \\ Romanian Academy, National Institute of Economic Research "Costin C. Kiritescu", Bucharest, \\ Romania \\ madalina_meghisan@yahoo.com
}

PICBE |

1045

Dorin TOMA

Clinical Hospital "Prof. Dr. Th. Burghele", Bucharest, Romania

dorintoma017@gmail.com

\begin{abstract}
The traditional public health care system should move forward towards prevention by building a strong brand strategy. Taking into consideration the health care expenditure, the paper focuses on the analysis of heath determinants: body mass index, physical activity, consumption of fruits and vegetables, tobacco consumption, alcohol consumption, social environment in connection to the unmet needs for health care: financial reasons, distance or transportation, waiting list. In the context of the competition coming from private health care institutions, the branding strategy of the public health care system should increase customer satisfaction and trust in order to obtain customer affective commitment and awareness. The approach focuses on factor analysis used to validate the following hypothesis: H1. The main heath determinants are: body mass index, physical activity, consumption of fruits and vegetables, tobacco consumption, alcohol consumption, social environment; H2. The main reasons for self-reported unmet needs for health care are: financial reasons, distance or transportation, waiting list. Due to the rapid development of information technology, public health care systems should integrate these technological advances in their structure, with emphasize on brand strategy. The paper has the following structure: after the Introduction, the Literature review part covers issues connected to brand experience, health determinants, health care needs within the EU-28 member states. Section 3 underlines the research methodology, using factor analysis as main method of macroeconomic data interpretation. The next section includes the results of the research, while the Conclusions part focuses on the main ideas of this research, together with the limits of the current approach. However, the research has some limits caused by the availability of up to date statistics and longer time series for the analyzed variables. We intend to further develop our research by introducing in the analysis other health care related variables within the European Union member states and other countries.
\end{abstract}

Keywords: branding, public health care system, health determinants, health care expenditure, strategy.

\section{Introduction}

Nowadays, the main issues the countries of European Union are facing are "the declining of birth rate and the rising of the life expectancy" (Cristea et al., 2016). This issue was partially solved by the international migration flows, especially in the states from Western Europe (36\%), totalizing "76 million migrants in 2015 in Europe" (Cristea et al., 2018). Good health 
system is build around a quality system and a strong brand, which need a solid funding mechanism.

In this paper we want to underline the main health determinants (body mass index, physical activity, consumption of fruits and vegetables, tobacco consumption, alcohol consumption, social environment.), together with the main the self-reported unmet needs for health care (financial reasons, distance or transportation, waiting list) in connection to building a strong brand in the public health care system within the countries of the EU-28.

The approach focuses on factor analysis used to validate the following hypothesis:

H1. The main heath determinants are: body mass index, physical activity, consumption of fruits and vegetables, tobacco consumption, alcohol consumption, social environment.

H2. The main reasons for self-reported unmet needs for health care are: financial reasons, distance or transportation, waiting list.

The paper has the following structure: after the Introduction, the Literature review part covers issues connected to brand experience, health determinants, health care needs within the EU-28 member states. Section 3 underlines the research methodology, using factor analysis as main method of macroeconomic data interpretation. The next section includes the results of the research, while the Conclusions part focuses on the main ideas of this research, together with the limits of the current approach.

\section{Literature review}

Brand experience is the main factor for the "takeaway impressions created in the minds of consumers" as a result of their interaction with several brands within a country. (Iglesias et al., 2019) In the public health care industry, there can be direct interactions (acquisition, purchase, consumption etc.) or indirect interactions (marketing strategy, word-of-month opinions, reviews, journal articles etc.). (Brakus et al., 2009)

Several studies emphasized the influence of heath determinants on human heath. Sedentary behavior can lead to: "muscle atrophy", "gain in fat", "diabetes", "cancer", "cardiovascular diseases" and other causes of mortality. (Biswas et al., 2015; Keadle et al., 2017) For instance, eventhough some persons have an intense physical activity, they spend their time after in a sedentary activity with negative effects on health. (Lynch, 2010) However, "the relevance of business climate is widely used in various analyses" (Dascalu et al., 2016), with possible influences on the current health determinants for employees.

The health care needs can be defined as "the capacity to benefit from health care". (Lee et al., 2015; Ahs et al., 2012) Several studies underlined the determinants of unmet needs: "unemployment", "chronic conditions and distress", "gender". (Stevens \& Gillam, 1998; Allin \& Grignon, 2010; Chen \& Hou, 2002) Other studies reveled the following unmet needs: "felt would be inadequate", "too busy", "didn't get around it", dislike doctors", "decided not to seek care". (Allin and Grignon, 2010)

According to several research results, gross direct product (GDP) is "significantly causally related to health expenditure". (Khandelwal, 2015) Other results show that in some studied countries, there is "excessive health expenditure" (Chang \& Ying, 2006). This increase in health care expenditure is closely linked to the "income level and economic growth of a country" (Mladenovic et al., 2016). Other researchers link the health care spending by national governments to "better outcomes, such as high life expectancy or 
longevity". (Han and Rizzo, 2017; Kim and Lane, 2013) However, the increasing of health care expenditure in countries from Western Europe is the result of health care national policies "to reduce health care costs by, for example, strengthening primary care". (Schafer et al., 2016) Health care expenditure represents "the economic resources dedicated to health functions, excluding capital investment". (EUROSTAT, 2019)

Health care expenditure by function divides the current health care expenditure depending on the purpose: curative care ("relieve symptoms or reduce the severity of an illness or injury") and rehabilitative care ("improve or restore impaired body functions and 1047 structures"); curative care; inpatient curative ("the treatment and/ or care provided in a healthcare facility to patients formally admitted and requiring an overnight stay"); rehabilitative care and inpatient curative care. (https://ec.europa.eu/eurostat/cache/metadata/en/hlth_sha11_esms.htm, accessed 02.03.2019)

Health care expenditure by financing scheme implies the financing with the following purpose "direct payments by households for services and goods and third-party financing arrangements", through: government schemes ("healthcare financing schemes whose characteristics are determined by law or by the government"); compulsory contributory health insurance scheme ("ensures access to healthcare for specific population groups through mandatory participation determined by law or by government"); compulsory medical savings accounts ("the basic method for fund-raising and some issues concerning the use of the account to pay for health services that are regulated by government"); voluntary health insurance schemes ("purchase of a health insurance policy, which is not made compulsory by government"). (https://ec.europa.eu/eurostat/cache/metadata/en/hlth_sha11_esms.htm, accessed 02.03.2019)

Health care expenditure by provider focuses on "the organizations and actors that deliver healthcare goods and services as their primary activity", such as: hospitals ("the licensed establishments that are primarily engaged in providing medical, diagnostic and treatment services"); general hospitals; mental health hospitals; specialized hospitals, other than mental health hospitals. (https://ec.europa.eu/eurostat/cache/metadata/en/hlth_sha11_esms.htm, accessed 02.03.2019)

\section{Methodology}

At the level of the year 2016, Germany was the country with the highest amount of heath care expenditure (350.221,00 mil. euro), followed by France (257.194,38 mil. euro), United Kingdom (233.886,44 mil. euro), Italy (150.201,00 mil. euro) and Spain $(100.335,78$ mil. euro). At the other end, the countries with the lowest amount of money for health care expenditure, for the year 2016, are: Ciprus (1.253,41 mil. euro), Estonia $(1.410,14$ mil. euro), Latvia (1.556,09 mil. euro). (Figure 1) 


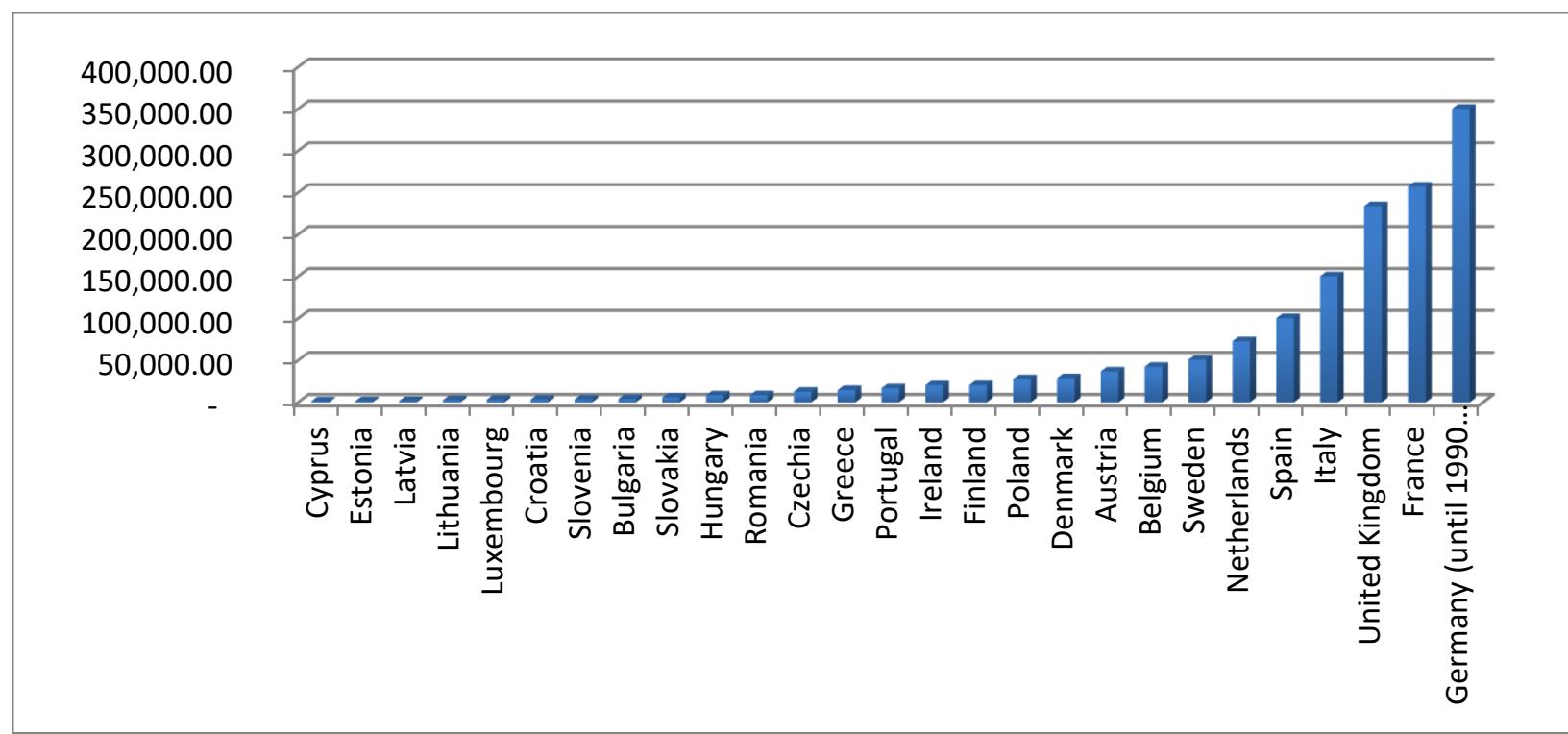

Figure 1. Current health care expenditure by function (2016)

Source:

https://ec.europa.eu/eurostat/web/health/data/database?p_p_id=NavTreeportletprod_WAR_NavTreeportlet prod_INSTANCE_HBRnpDQkQkPD\&p_p_lifecycle $=0 \&$ p_p_state $=$ normal\&p_p_mode $=$ view\&p_p_col_id $=$ column-

2\&p_p_col_count=1, accessed 01.03.2019

However, if we take into consideration the population of each EU-28 member states at the level of the year 2016, there can be underlined that the countries with the highest current health care expenditure compared to the number of population, are (Figure 2):

- Luxembourg (3.266,68 mil. euro for current health care expenditure and a population of 0,57 mil. pers.);

- Sweden (50.867,15 mil. euro for current health care expenditure and a population of 9,85 mil. pers.);

- Denmark (28.720,24 mil. euro for current health care expenditure and a population of 5,70 mil. pers.);

- Ireland (20.332,18 mil. euro for current health care expenditure and a population of 4,72 mil. pers.);

- Netherlands (72.788,83 mil. euro for current health care expenditure and a population of 16,97 mil. pers.);

The EU-28 states with the lowest current health care expenditure compared to the number of population, at the level of the year 2016, are (Figure 2):

- Romania (8.511,15 mil. euro for current health care expenditure and a population of 19,76 mil. pers.);

- Bulgaria (3.960,50 mil. euro for current health care expenditure and a population of 7,15 mil. pers.);

- Poland (27.756,39 mil. euro for current health care expenditure and a population of 37,96 mil. pers.); 


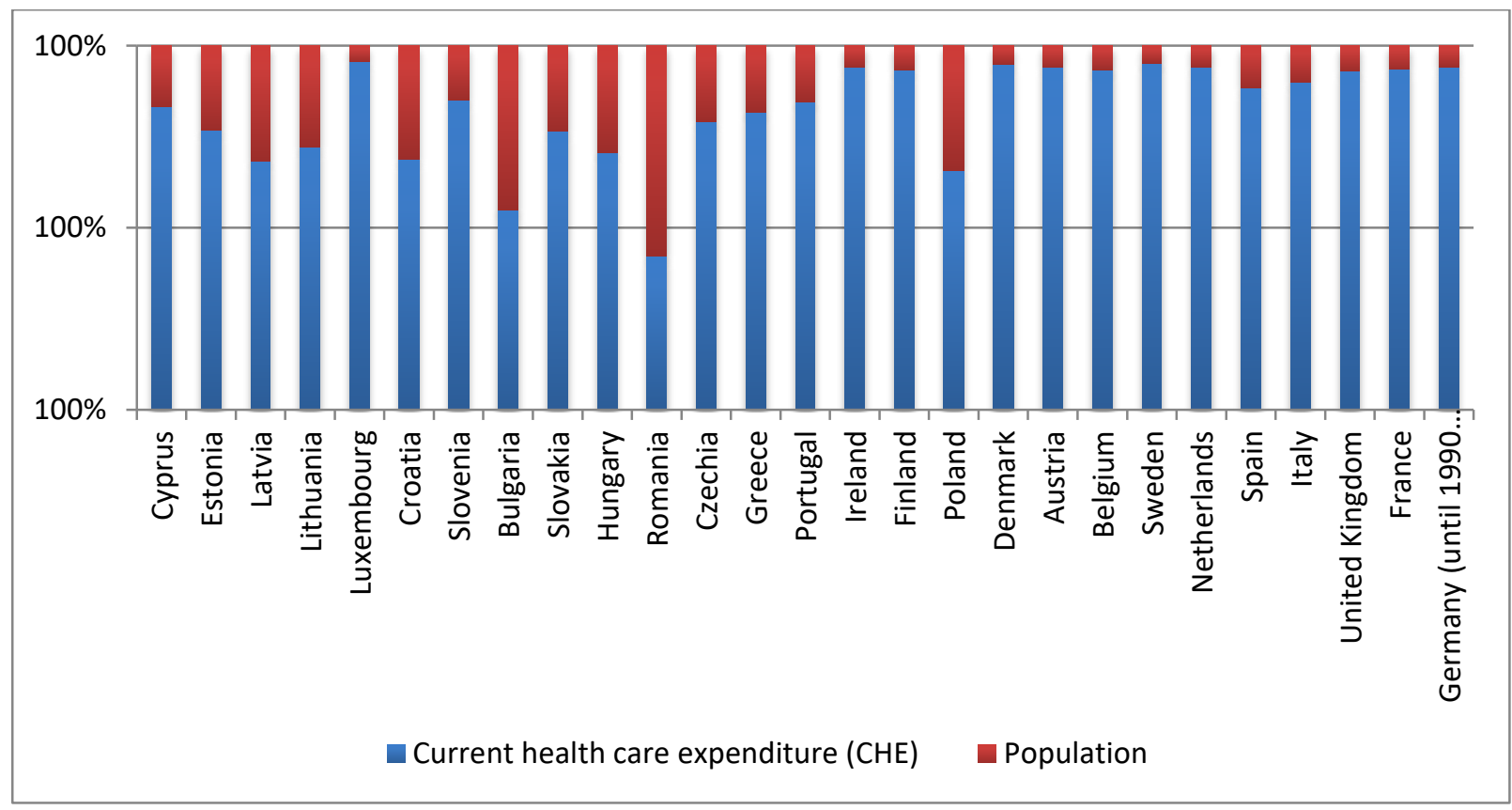

PICBE | 1049

Figure 2. Current health care expenditure (Mil. euro) vs. Population (mil. pers) (2016)- \% Source: https://ec.europa.eu/eurostat/web/population-demography-migrationprojections/data/main-tables, accessed 03.03.2019

Analyzing the current health care expenditure divided to the number of population for each EU-28 state, at the level of the year 2016, the states with the highest amount of money are (Figure 3):

- Luxembourg (an average of 5.668,87 euro for current health care expenditure for one person);

- Sweden (an average of 5.163,64 euro for current health care expenditure for one person);

- Denmark (an average of 5.032,24 euro for current health care for one person);

- Ireland (an average of 4.301,94 euro for current health care expenditure for one person);

- Netherlands (an average of 4.286,96 euro for current health care expenditure for one person);

The EU-28 states with the lowest current health care expenditure reported to the number of population, at the level of the year 2016, are (Figure 3):

- Romania (an average of 430,72 euro for current health care expenditure for one person);

- Bulgaria (an average of 553,62 euro for current health care expenditure for one person);

- Poland (an average of 731,06 euro for current health care expenditure for one person); 


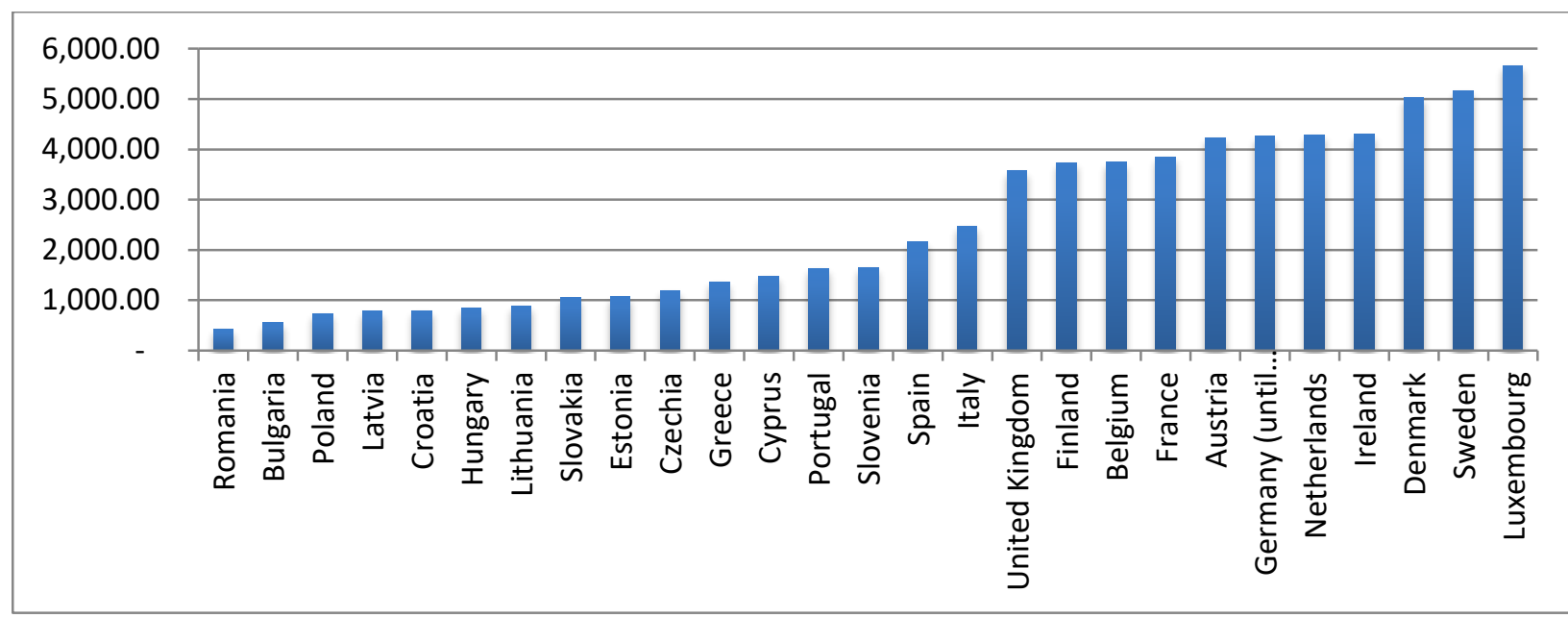

PICBE | 1050

Figure 3. Current health care expenditure (Mil. euro) divided to the number of population (mil. pers) (2016)

Source: $\quad$ https://ec.europa.eu/eurostat/web/population-demography-migrationprojections/data/main-tables, accessed 03.03.2019

H1. The main heath determinants are: body mass index, physical activity, consumption of fruits and vegetables, tobacco consumption, alcohol consumption, social environment. The health determinants include "various individual and environmental health determinants" (Eurostat, 2019).

For each of the EU-28 member states, a series of variables were chosen to be part of the factor analysis, based on their availability on Eurostat Database for the year 2014. (Table 1)

Table 1. Health determinants variables

\begin{tabular}{|l|l|}
\hline \multicolumn{2}{|l|}{ Variables } \\
\hline Body mass index (2014) & Underweight \\
\hline & Normal weight \\
\hline & Obese \\
\hline Physical activity (2014) & Aerobic \\
\hline Consumption of fruits and vegetables (2014) & Muscle strengthening \\
\hline & Consumption of 0 portions of fruits and vegetables \\
\hline & Consumption from 1 to 4 portions of fruits and vegetables \\
\hline Tobacco consumption (2014) & Consumption of 5 portions or more of fruits and vegetables \\
\hline & Non-smoker \\
\hline & Daily smoker \\
\hline Alcohol consumption (2014) & Occasional smoker \\
\hline & Every day alcohol consumption \\
\hline & Every week alcohol consumption \\
\hline & Every month alcohol consumption \\
\hline & Less than once a month \\
\hline Social environment (2014) & Never or not in the last 12 months alcohol consumption \\
\hline & Strong social environment \\
\hline & Intermediate social environment \\
\hline & Poor social environment \\
\hline &
\end{tabular}

Source: Authors' own research. 
Using factor analysis, we carried out a dimension reduction in order to define one or more health determinants within the EU-28 member states. The value of the Kaiser-MeyerOlkin test is 0,633 , with Sig. $<0.05$. (Table 2)

Table 2. KMO and Bartlett's Test

\begin{tabular}{|l|l|r|}
\hline \multicolumn{2}{|c|}{ KMO and Bartlett's Test } \\
\hline Kaiser-Meyer-Olkin Measure of Sampling Adequacy. & 0,633 \\
\hline \multirow{3}{*}{ Bartlett's Test of Sphericity } & Approx. Chi-Square & 61,413 \\
\cline { 2 - 3 } & df & 3 \\
\cline { 2 - 3 } & Sig. & 0,000 \\
\hline
\end{tabular}

Source: Authors' own research using SPSS 20.00 for Windows.

According to the data from the Table 3 , there were eliminated the items with a value lower than 0,5: Underweight; Normal weight; Obese; Consumption of 0 portions of fruits and vegetables; Consumption from 1 to 4 portions of fruits and vegetables; Consumption of 5 portions or more of fruits and vegetables; Non-smoker; Daily smoker; Occasional smoker; Every day alcohol consumption; Every month alcohol consumption; Never or not in the last 12 months alcohol consumption; Less than once a month alcohol consumption; Strong social environment; Intermediate social environment; Poor social environment.

Table 3. Communalities

\begin{tabular}{|l|r|r|}
\hline \multicolumn{2}{|c|}{ Communalities } \\
\hline & \multicolumn{1}{|c|}{ Initial } & Extraction \\
\hline Aerobic & 1,000 & 0,891 \\
\hline Muscle strengthening & 1,000 & 0,920 \\
\hline Every week alcohol consumption & 1,000 & 0,618 \\
\hline Extraction Method: Principal Component Analysis. & & \\
\hline
\end{tabular}

Source: Authors' own research using SPSS 20.00 for Windows.

The explained variance table presents one factor with a value superior to 1 (2.429). The Table 4 of the total variance explained presents one dimension that resumes the information. The first dimension explains $80,967 \%$ of the variation of the phenomenon. (Table 4)

Table 4. Total variance explained

\begin{tabular}{|l|r|r|r|r|r|r|}
\hline \multicolumn{7}{|c|}{ Total Variance Explained } \\
\hline \multirow{2}{*}{ Component } & \multicolumn{7}{|c|}{ Initial Eigenvalues } & \multicolumn{2}{c|}{ Extraction Sums of Squared Loadings } \\
\cline { 2 - 7 } & Total & \% of Variance & Cumulative \% & Total & \% of Variance & Cumulative \% \\
\hline 1 & 2,429 & 80,967 & 80,967 & 2,429 & 80,967 & 80,967 \\
\hline 2 & 0,515 & 17,150 & 98,117 & & & \\
\hline 3 & 0,056 & 1,883 & 100,000 & & & \\
\hline \multicolumn{7}{|l|}{ Extraction Method: Principal Component Analysis. } \\
\hline
\end{tabular}

Source: Authors' own research using SPSS 20.00 for Windows. 
The results from the Table 5 underline the definition of health determinants: Aerobic $(0,944)$; Muscle strengthening $(0,959)$; Every week alcohol consumption $(0,786)$.

Table 5. Component matrix

\begin{tabular}{|l|r|}
\hline \multicolumn{2}{|c|}{ Component Matrix } \\
\hline \multicolumn{2}{|c|}{} \\
\cline { 2 - 2 } & \multicolumn{1}{|c|}{ Component } \\
\hline Aerobic & 1 \\
\hline Muscle strengthening & 0,944 \\
\hline Every week alcohol consumption & 0,959 \\
\hline Extraction Method: Principal Component Analysis. & 0,786 \\
\hline a. 1 components extracted. & \\
\hline
\end{tabular}

The next step consists in determining the viability of the scale, using the coefficient Cronbach's 'alpha. Carrying on the analysis, we can confirm that the scale has an acceptable viability of internal coherence, the value of Cronbach's alpha being 0,8720. (Table 6)

Table 6. Reliability statistics

\begin{tabular}{|lr|r|}
\hline \multicolumn{3}{|c|}{ Reliability Statistics } \\
\hline Cronbach's Alpha & 0,872 & N of Items \\
\hline & & \\
\hline
\end{tabular}

Source: Authors' own research using SPSS 20.00 for Windows.

As the results reveal, the main important issues regarding the health determinants are Physical activity and Alcohol consumption. This result can be justified by the public health campaigns regarding the alcohol consumption and various opportunities of physical activity (aerobic and muscle strengthening). The connection between branding and health determinants can be underlined by emphasizing several other public health care campaigns for: "height and weight"; "consumption of fruits, vegetables and juice"; "smoking behavior and exposure to tobacco smoke"; "social support"; "provision of informal care or assistance"; "illicit drug use"; "home and workplace exposure"; "criminality exposure". (Eurostat, 2019)

H2. The main reasons for self-reported unmet needs for health care are: financial reasons, distance or transportation, waiting list.

For each of the EU-28 member states, the variables chosen for the factor analysis underline the self-reported unmet needs for health care, available on Eurostat Database for the year 2014. (Table 7)

Table 7. Variables of self-reported unmet needs for health care

\begin{tabular}{|l|l|}
\hline \multicolumn{2}{|c|}{ Variables } \\
\hline Self-reported unmet needs for health care (2014) & Financial reasons \\
\hline & Distance or transportation \\
\hline & Waiting list \\
\hline
\end{tabular}

Source: Authors' own research 
Using the factor analysis, the purpose is to define the variables for self-reported unmet needs for health care. The value of Kaiser-Meyer-Olkin test is 0,675, with Sig.<0,5. (Table 8)

Table 8. KMO and Bartlett's Test

\begin{tabular}{|l|l|r|}
\hline \multicolumn{2}{|c|}{ KMO and Bartlett's Test } \\
\hline \multirow{2}{*}{ Kaiser-Meyer-Olkin Measure of Sampling Adequacy. } & 0,675 \\
\hline \multirow{3}{*}{ Bartlett's Test of Sphericity } & Approx. Chi-Square & 18,915 \\
\cline { 2 - 3 } & df & 3 \\
\cline { 2 - 3 } & Sig. & 0,000 \\
\hline
\end{tabular}

Source: Authors' own research using SPSS 20.00 for Windows.

According to the data from the Table 9, all the items have a value higher than 0,5: Financial reasons; Distance or transportation; Waiting list.

Table 9. Communalities

\begin{tabular}{|l|r|r|}
\hline \multicolumn{2}{|c|}{ Communalities } \\
\hline & \multicolumn{1}{|c|}{ Initial } & Extraction \\
\hline Financial reasons & 1,000 & 0,647 \\
\hline Distance or transportation & 1,000 & 0,750 \\
\hline Waiting list & 1,000 & 0,640 \\
\hline Extraction Method: Principal Component Analysis. & & \\
\hline
\end{tabular}

Source: Authors' own research using SPSS 20.00 for Windows.

The first dimension allows us to explain $67,898 \%$ of the variation of the phenomenon. According to the theory in the field, we can stop the process of factor extraction if we reach $60 \%$ of the cumulated variance extracted. (Table 10)

Table 10. Total variance explained

\begin{tabular}{|l|r|r|r|r|r|r|}
\hline \multicolumn{7}{|c|}{ Total Variance Explained } \\
\hline \multirow{2}{*}{ Component } & \multicolumn{7}{|c|}{ Initial Eigenvalues } & \multicolumn{2}{c|}{ Extraction Sums of Squared Loadings } \\
\cline { 2 - 7 } & Total & \% of Variance & Cumulative \% & Total & $\%$ of Variance & Cumulative \% \\
\hline 1 & 2,037 & 67,898 & 67,898 & 2,037 & 67,898 & 67,898 \\
\hline 2 & 0,568 & 18,924 & 86,822 & & & \\
\hline 3 & 0,395 & 13,178 & 100,000 & & & \\
\hline \multicolumn{7}{|l|}{ Extraction Method: Principal Component Analysis. } \\
\hline
\end{tabular}

Source: Authors' own research using SPSS 20.00 for Windows.

According to the results from the Table 11, the indicators for the self-reported unmet needs for health care are: financial reasons $(0,804)$, distance or transportation $(0,866)$ and waiting list $(0,800)$. 
Table 11. Component matrix

\begin{tabular}{|l|r|}
\hline \multicolumn{2}{|c|}{ Component Matrix ${ }^{\mathbf{a}}$} \\
\hline & \multicolumn{1}{|c|}{ Component } \\
\cline { 2 - 2 } & \multicolumn{1}{|c|}{1} \\
\hline Financial reasons & 0,804 \\
\hline Distance or transportation & 0,866 \\
\hline Waiting list & 0,800 \\
\hline Extraction Method: Principal Component Analysis. & \\
\hline a. 1 components extracted. & \\
\hline
\end{tabular}

The scale has an acceptable viability of internal coherence. The value of Cronbach's Alpha is 0,614. (Table 12)

Table 12. Reliability statistics

\begin{tabular}{|lr|r|}
\hline \multicolumn{3}{|c|}{ Reliability Statistics } \\
\hline Cronbach's Alpha & & N of Items \\
\hline & 0,614 & 3 \\
\hline
\end{tabular}

Source: Authors' own research using SPSS 20.00 for Windows.

The self-reported unmet needs for medical examination reveal financial reasons; distance or transportation; waiting list. In some countries the medical system is under financed, that's why patients have more trust to go to private health care providers, which implies a cost for them. Other patients that live in rural areas may encounter barriers of distance or transportation facility in order to benefit from medical examination. Moreover, for the patients from the public health care system there is always a waiting list that can sometimes refrain the medical examination.

There can be taken into consideration several solutions from the point of view of creating a brand trust in public health care system: drive public campaigns in order to accommodate people to the medical act from childhood, through preventive health care controls; drive public campaigns on the importance of prevention than heal, through medical act.

At the same time, in the public healthcare system: should be redirecting more financing means; the accessibility to health examination should be improved and should be hired enough medical staff in order to diminish the waiting lists.

\section{Results and discussions}

The health care system should focus mainly on prevention of sedentary behavior and other unhealthy habits. Building brand trust, the public health care system should focus more on the patient in strong connection with the health determinants.

The most representative health determinants across EU-28 states are (Table 12):

- Health determinants: aerobic (with variations from $0 \%$ to $54,60 \%$ at the level of EU28); 
- Health determinants: muscle strengthening (with variations from $0 \%$ to $39,40 \%$ at the level of EU-28);

- Health determinants: every week alcohol consumption (with variations from $12 \%$ to $45,90 \%$ at the level of EU-28)

Table 12. Descriptive statistics for the main health determinants

\begin{tabular}{|l|r|r|r|r|r|}
\hline \multicolumn{7}{|c|}{ Descriptive Statistics } \\
\hline & N & \multicolumn{1}{|c|}{ Minimum } & Maximum & \multicolumn{1}{c|}{ Mean } & \multicolumn{1}{c|}{ Std. Deviation } \\
\hline Aerobic & 28 & 0,00 & 54,60 & 29,2286 & 14,34002 \\
\hline Muscle strengthening & 28 & 0,00 & 39,40 & 17,2607 & 10,88435 \\
\hline $\begin{array}{l}\text { Every week alcohol } \\
\text { consumption }\end{array}$ & 28 & 12,90 & 45,00 & 26,5815 & 10,37479 \\
\hline Valid N (listwise) & 28 & & & & \\
\hline
\end{tabular}

PICBE | 1055

The most representative self-reported unmet needs for health care, across EU-28 states are (Table 13):

- Self-reported unmet needs for health care: financial reasons (with variations from $4,90 \%$ to $35,90 \%$ at the level of EU-28);

- Self-reported unmet needs for health care: distance or transportation (with variations from $0,10 \%$ to $9,10 \%$ at the level of EU-28);

- Self-reported unmet needs for health care: waiting list (with variations from $2,40 \%$ to $31,00 \%$ at the level of EU-28)

Table 13. Descriptive statistics for variables of self-reported unmet needs for health care

\begin{tabular}{|l|r|r|r|r|r|}
\hline \multicolumn{7}{|c|}{ Descriptive Statistics } \\
\hline & N & Minimum & Maximum & \multicolumn{1}{c|}{ Mean } & \multicolumn{1}{c|}{ Std. Deviation } \\
\hline Financial reasons & 28 & 4,90 & 35,90 & 16,0074 & 8,61144 \\
\hline Distance or transportation & 28 & 0,10 & 9,10 & 3,5889 & 2,10555 \\
\hline Waiting list & 28 & 2,40 & 31,00 & 17,8000 & 7,87640 \\
\hline Valid N (listwise) & 28 & & & & \\
\hline
\end{tabular}

Source: Authors' own research using SPSS 20.00 for Windows.

\section{Conclusion}

In this article current health determinants and self-reported unmet needs for health care are considered from the point of view of building a strong brand strategy in public health care system. Doctors in managerial position play an important role in raising brand awareness and increasing hospital performance. In services, quality assess plays an important role among the clients. The main characteristics of quality health are: "efficiency, accessibility, equality and integrated way with the help of clinicians and managers" (Novac \& Djordjevic, 2019) Thus public health institutions should integrate these characteristics in order to develop and increase brand trust. 
Due to the rapid development of information technology, public health care systems should integrate these technological advances in their structure, with emphasize on brand strategy. "Clinical quality depends on systems" (Novac \& Djordjevic, 2019), in order to fulfill the gap between health determinants on one hand, and if possible try to eliminate the self-reported unmet needs for health care.

However, the research has some limits caused by the unavailability of up to date statistics and longer time series for the analyzed variables. We intend to further develop our research by introducing in the analysis other health care related variables.

\section{References}

Ahs, A., Burell, G. \& Westerling, R. (2012). Care or not care- that is the question: predictors of healthcare utilization in relation to employment status. International Journal of Behavioral Medicine, 19, 29-38.

Allin, S., Grignon, M., \& Le Grand, J. (2010). Subjective unmet need and utilization of health care services in Canada: what are the equity implications?. Social Science and medicine, 70, 465-472.

Biswas, A., Faulkner, P.I., Bajaj, R.R., Silver, M.A., Mitchell, M.S., et al. (2015). Sedentary time and its association with risk for disease incidence, mortality and hospitalization in adults: a systematic review and meta-analysis. Ann Intern Med, 162, 123-132.

Brakus, J.J., Schmitt, B.H., \& Zarantonello, L. (2009). Brand experience: What is it? How is it measured? Does it affect loyalty? Journal of Marketing, 73(3), 52-68.

Chang, K., \&Ying, Y.H. (2006). Economic growth, human capital investment and health expenditure: A study of OECD countries. Hitotsubashi Journal of Economics, 47, 1-16.

Chen, J. \& Hou, F. (2002). Unmet needs for health care. Health Reports, 13, 23-34.

Cristea, M., Marcu, N., \& Cercelaru, O.V. (2016). Longer life with worsening pension system? Aging population impact on the pension system in two countries: Romania and Croatia. Economic and Social Development: Book Proceedings, 6(9), 28.

Dascalu, D.E., Marcu, N., Pete, S., Ulici, M.L., \& Dumitrascu, V. (2016). Dependent business climate. A network-based analysis. Romanian Journal of Economic Forecasting, 3, 30.

Han, M., \& Rizzo, J.A. (2017). The health returns to medical expenditure: Does age matter? Retrieved from: http://www.hec.ca/iea/seminaires/121113_john_rizzo.pdf.

Iglesias, O., Markovic, S., \& Rialp, J. (2019). How does sensory brand experience influence brand equity? Considering the roles of customer satisfaction, customer affective commitment, and employee empathy. Journal of Business Research, 96, 343-354.

Kimm, T.K., \& Lane, S.R. (2013). Government health expenditure and public health outcomes: A comparative study among 17 countries and implications for US health care reform. Am Int J Contemp Res., 3, 8-13.

Khandelwal, V. (2015). Impact of energy consumption, GDP \& Fiscal deficit on public health expenditure in India: An ARDL bounds testing approach. Energy Procedia, 75, 26582664.

Lee, S.Y., Kim, C.W., Kang, J.H., \& Seo, N.K. (2015). Unmet healthcare needs depending on employment status. Health Policy, 119, 899-906.

Lynch, B.M. (2010). Sedentary behavior and cancer: a systematic review of the literature and proposed biological mechanisms. Cancer Epidemiol Biomarkers Prev., 19, 26912709. 
Mladenovic, I., Milovancevic, M., Cokolov Mladenovic, S., Marjanovic, V., Petkovic, B. (2016). Analyzing and management of health care expenditure and gross domestic product (GDP) growth rate by adaptive neuro-fuzzy technique. Computers in Human Behavior, 64, 524-530.

Noja, G.G., Cristea, S.M., Yuksel, A., Panzaru, C., \& Dracea, M.R. (2018). Migrants' role in enhancing the economic development of host countries: empirical evidence from Europe. Sustainability, 10(3), 894.

Novak, S., \& Djordjevic, N. (2019). Information system for evaluation of healthcare expenditure and health monitoring. Physica A, 520, 72-80.

Schafer, W.L., Boerma, W.G., Spreeuwenberg, P. et al. (2016). Two decades of change in European general practice service profiles: Conditions associated with the development in 28 countries between 1993 and 2012. Scand J Prim health Care, 34, $97-110$.

Stevens, A. \& Gillam, S. (1998). Needs assessment: from theory to practice. British Medical Journal, 316, 1448-1452.

EUROSTAT, https://ec.europa.eu/eurostat/cache/metadata/en/hlth_sha11_esms.htm, accessed 02.03.2019.

EUROSTAT,https://ec.europa.eu/eurostat/web/health/data/database?p_p_id=NavTreepor tletprod_WAR_NavTreeportletprod_INSTANCE_HBRnpDQkQkPD\&p_p_lifecycle=0\&p _p_state $=$ normal\&p_p_mode $=$ view\&p_p_col_id $=$ column-2\&p_p_col_count $=1$, accessed 01.03.2019.

EUROSTAT, https://ec.europa.eu/eurostat/web/population-demography-migrationprojections/data/main-tables, accessed 03.03.2019. 